\title{
Evaluation of human hydatid disease before and after surgery and chemotherapy by demonstration of hydatid antigens and antibodies in serum
}

\author{
P. T. RAVINDER, S. C. PARIJA and K. S. V. K. SUBBA RAO* \\ Departments of Microbiology and ${ }^{*}$ Cardio-Thoracic Surgery, Jawaharlal Institute of Postgraduate Medical \\ Education and Research, Pondicherry, India
}

\begin{abstract}
This study was performed to differentiate serologically between patients with hydatid disease which is active, and which has been successfully cured. A total of 18 cases was included. Pre-treatment serum samples were collected before surgery or chemotherapy. Post-treatment serum samples were collected at various intervals ( 3 days, 7 days, 1 month, 6 months, 1 year and 2 years) after surgery or chemotherapy. These sera were tested for the presence of circulating hydatid antigen (CAg) by bacterial co-agglutination (Co-A) and counter-current immunoelectrophoresis (CIEP) tests, and for circulating hydatid antibodies (CAb) by indirect haemagglutination assay (IHA). Ten and eight sera, respectively, were positive out of 11 pre-operative and pre-chemotherapeutic sera tested for CAg by the Co-A and CIEP tests. Post-operative sera collected from these cases did not show any CAg by the CIEP test. However, $\mathrm{CAg}$ was detected by $\mathrm{Co}-\mathrm{A}$ in three and four serum samples collected on the third and seventh day, respectively, after surgical removal of the cyst. However, the CAg levels in these post-operative sera showed a gradual decline by the seventh day and were completely absent in the serum specimens collected 1 month after surgery and 6 months after chemotherapy. All the post-operative serum samples except two, collected 2 years after surgical removal of the cyst, in seven cases of old hydatid disease, were negative for CAg by both the CIEP and Co-A tests. Unlike the CAg profile, no marked differences were noted between the $\mathrm{CAb}$ profile of the pre- and post-treatment sera, as shown by the IHA test. Even 1 year after surgery or chemotherapy, two sera showed a marginal decrease in their CAb titre. CAb at varying titres was still detectable in all seven serum samples from old cases of hydatid disease, even 2 years after surgical removal of the cyst. This study shows the value of serial pre- and post-operative or chemotherapy estimation of CAg by Co-A and CIEP as an index of cure or of continuing hydatid infection.
\end{abstract}

\section{Introduction}

Hydatid disease is a silent cyclozoonotic infection of man and domestic animals caused by the larvae of the cestode Echinococcus granulosus [1]. It is cosmopoli$\tan$ in distribution with several regional peculiarities [2]. Man becomes infected accidentally by ingestion of eggs of the parasite through hands or food, drink or other materials contaminated with dog faeces. Hydatid disease in man is a serious condition and the surgical removal of cysts remains the mainstay of treatment.

Received 3 July 1996; revised version accepted 21 Feb. 1997.

Corresponding author: Professor S. C. Parija. Present address: Department of Microbiology, BP Koirala Institute of Health Sciences, Dharan, Nepal.
Serological tests are important in the diagnosis of hydatid disease [3]. These tests help in the detection of cases and in the serosurveillance of hydatid disease in the community. In addition to these, another suggested use of hydatid serology is the evaluation of cases of hydatid disease pre- and post-surgery and chemotherapy [4]. Hydatid serology is based largely on the detection of circulating hydatid antibodies $(\mathrm{CAb})$ in the serum which occur frequently in established cystic hydatid infections. Indirect haemagglutination (IHA), the latex agglutination test (LAT), solid-phase radioimmunoassay (SPRIA) and enzymelinked immunosorbent assay (ELISA) are the usual serological tests for demonstration of hydatid antibodies in the serum [4]. Detection of circulating hydatid antigens (CAg) in the serum and other body fluids by ELISA [5], counter-current immunoelectro- 
phoresis (CIEP) [6] and bacterial co-agglutination (Co-A) [7] are current approaches in hydatid serology.

After surgery or chemotherapy it is often difficult to be sure whether the patient is cured of hydatid disease or remains infected. This is a recognised problem in the management of hydatid disease, and is due to the persistence of small or ectopic cysts in other sites even after surgery, the possibility of secondary echinococcosis following surgery of hydatid cysts, or the development of resistance of cysts to chemotherapy [6]. The aim of the present study was to evaluate serological tests that might differentiate between infected and cured cases of hydatid disease. $\mathrm{CAg}$ and $\mathrm{CAb}$ profiles were determined in both preand post-operative or chemotherapy sera. CIEP and Co-A tests were employed to detect CAg and IHA to detect $\mathrm{CAb}$ in the serum.

\section{Materials and methods}

\section{Sera}

Sera were collected from 18 patients with hydatid disease at the Jawaharlal Institute of Postgraduate Medical Education and Research (JIPMER) Hospital, Pondicherry, India as described below.

Cases treated by surgical operation. New cases: this group included six new cases of hydatid disease operated on for hydatid cysts (SC). A single preoperative serum sample was collected from each patient before surgery. After surgery, a minimum of one serum sample was collected from these patients, either at 3 days, 7 days, 1 month, 6 months or 1 year, depending upon the contact with patients during the follow-up of these cases. In addition to these cases, seven 'old' cases of hydatid disease who were operated on 2 years previously were also followed up and included in the study. A single post-operative serum sample was collected from each case.

Cases treated by chemotherapy. This group included three cases of ultrasound-proven hydatid disease (USP) and two cases of presumptive hydatid disease (PHD). The latter cases presented clinical signs and symptoms strongly suggestive of hydatid disease and their sera showed a diagnostic hydatid antibody titre $(\geqslant 128)$ by the IHA [8]. These cases were treated by chemotherapy only and not with surgery. A single serum sample was collected from these patients before starting chemotherapy. After chemotherapy, sera were collected from three and two of these patients after 6 months and 1 year respectively. The sera were stored at $-20^{\circ} \mathrm{C}$ until used.

\section{Hydatid antigen}

Crude human hydatid cyst fluid (HHCF) was used as hydatid antigen. The hydatid fluid was obtained from lung, liver and abdominal hydatid cysts at surgery and was processed according to the method described by Parija and Rao [9]. The hydatid fluid was aspirated aseptically and checked for the presence of scolices and hooklets. The fluid was filtered through a Seitz filter and checked for sterility by aerobic culture.

\section{Hyperimmune antiserum}

Human hydatid cyst fluid was emulsified with an equal volume of Freund's complete adjuvant. Adult rabbits $(3-4 \mathrm{~kg})$ were given $0.5 \mathrm{ml}$ of this emulsion in all four limbs intramuscularly (i.m.). After 6 weeks, they were given a further $0.5 \mathrm{ml}$ in each limb (i.m.) of the same antigen in Freund's incomplete adjuvant. After 10 days, blood samples were taken and monitored for hydatid antibodies to HHCF antigen by IHA [8]. The blood was collected when the titre of antibodies was $\geqslant 1024$.

\section{Purification of antiserum}

Hyperimmune antiserum containing hydatid antibodies was purified by the method described by Gottstein [5]. Briefly, $1 \mathrm{ml}$ of cold serum was mixed with $1 \mathrm{ml}$ of cold saline at $\mathrm{pH} 7$. The serum-saline mixture $(2 \mathrm{ml})$ was added dropwise to $2 \mathrm{ml}$ of $50 \%$ cold saturated ammonium sulphate $(\mathrm{pH} \mathrm{7)}$, while stirring for $30 \mathrm{~min}$ on ice, and then centrifuged $\left(3000 \mathrm{rpm}\right.$ at $\left.0^{\circ} \mathrm{C}\right)$. The supernate was discarded and the precipitate was suspended in $2 \mathrm{ml}$ of saline and the procedure was repeated until the supernate was colourless. The final precipitate was suspended in $1 \mathrm{ml}$ of saline and dialysed against PBS ( $\mathrm{pH}$ 7.2) to remove all the residual ammonium sulphate. The titre of the purified antiserum was 2048 by the IHA [8].

\section{Hydatid antigen and antibody profiles}

The sera were screened for $\mathrm{CAg}$ and $\mathrm{CAb}$ profiles. CIEP [6] and Co-A [7] were employed to detect CAg and IHA [8] to detect CAb.

\section{Counter-current immunoelectrophoresis (CIEP)}

This test was performed with neat hyperimmune hydatid sera on a glass slide containing Bacto-agar (Difco) $1 \%$ as described by Shariff and Parija [6]. Briefly, the procedure consists of the following steps:

Preparation of slides. Gel was made on the glass slides with Bacto-agar $1 \%$. It was allowed to set at room temperature and thereafter stored at $4^{\circ} \mathrm{C}$ overnight before use.

CIEP test. Parallel rows of wells, $4 \mathrm{~mm}$ in diameter and $3 \mathrm{~mm}$ apart, were punched out on the slides with the aid of a template. Each well was filled with $10 \mu \mathrm{l}$ of the appropriate reactant. Wells containing hydatid antisera (titre 2048) were placed on the anodic side of 
the electrophoretic chamber and those containing antigen on the cathodic side. The chambers were filled with veronal buffer $(0.05 \mathrm{M}, \mathrm{pH} 8.4)$ and $8 \mathrm{~V} / \mathrm{cm}$ of current was applied for $30 \mathrm{~min}$. The CIEP slides were read unstained, immediately after electrophoresis, with the use of oblique lighting against a black background. The slides were stained and re-read. Positive reactions were defined by precipitation lines between antigen and hyperimmune serum. Positive and negative controls were included in each test.

\section{Bacterial co-agglutination}

This test was performed to detect CAg in the sera according to the procedure described by Shariff and Parija [7]. Briefly, it consisted of the following steps.

Preparation of bacterial cells. Staphylococcus aureus (Cowans' 1) cells bearing protein A (SAPA) were used. The cells were grown on Mueller-Hinton agar at $37^{\circ} \mathrm{C}$ for $18 \mathrm{~h}$, then harvested and centrifuged at $3000 \mathrm{~g}$ for $10 \mathrm{~min}$, washed three times in phosphate-buffered saline (PBS, $\mathrm{pH} \mathrm{7.2)} \mathrm{at} \mathrm{room} \mathrm{temperature} \mathrm{for} 90 \mathrm{~min}$, and resuspended in 10 volumes of the buffer containing sodium azide $0.05 \%$ and heated for $5 \mathrm{~min}$ at $80^{\circ} \mathrm{C}$. The SAPA cells were again washed three times and a $10 \%$ suspension in PBS ( $\mathrm{pH}$ 7.2) containing sodium azide $0.05 \%$ was made and then divided into small volumes and stored at $-20^{\circ} \mathrm{C}$.

Sensitisation of SAPA cells. The SAPA cells were sensitised with hyperimmune antiserum immediately after preparation of the cells. One $\mathrm{ml}$ of $10 \%$ stabilised cells was added to $0.1 \mathrm{ml}$ of specific antiserum (IHA titre 2048), mixed and left at room temperature for $30 \mathrm{~min}$. Then, the cells were washed and resuspended to a concentration of $2 \%$ in PBS ( $\mathrm{pH} 7.2$ ) containing sodium azide $0.1 \%$. The sensitised reagent was stored at $4^{\circ} \mathrm{C}$. A $2 \%$ suspension of unsensitised cells was used as the cell control.

Co- $A$ test. The slide was marked by a glass marking pen into two halves. A drop of test serum was placed on each half of the slide. An equal volume of $2 \%$ sensitised SAPA cell suspension was added to the serum on one half. The same volume of a $2 \%$ suspension of unsensitised SAPA cells was added to the serum on the other half as a cell control. The slide was then rotated manually for $2 \mathrm{~min}$ and inspected. Agglutination with the sensitised cells and not with unsensitised cells was considered to be a positive result.

The cell and negative controls (serum negative for hydatid antigen) in the slides were examined first, and endpoints of the reference positive and test sera were determined.

The antigen titre in the serum was estimated by performing a quantitative test with the serum diluted from 1 in 2 to 1 in 128. The highest dilution of serum showing agglutination was considered to be the Co-A titre.

\section{Indirect haemagglutination}

IHA was performed as described by Parija and Ananthakrishnan [8]. Briefly, it consisted of the collection of human blood group $\mathrm{O}$ cells followed by double aldehyde stabilisation (DAS), sensitisation with hydatid antigen and quantitation of the test by microdilution.

Twenty-five $\mu \mathrm{l}$ of diluent (PBS, $\mathrm{pH} 7.2$, with BSA $0.1 \%$ ) were dispensed in all the wells of a ' $U$ 'bottomed microtitration plate. An equal volume of serum was added to the first well and then serially diluted up to the eleventh well. DAS cells $(25 \mu \mathrm{l})$ sensitised with the optimum sensitising dose (OSD) of the hydatid antigen were then added to all the wells. The plate was gently rotated for $2 \mathrm{~min}$, then incubated at room temperature for $45 \mathrm{~min}$. A preliminary reading was taken followed by incubation at $4^{\circ} \mathrm{C}$ overnight. The final reading was taken on the following day.

\section{Results}

The results of the Co-A, CIEP and IHA tests are summarised in Table 1.

\section{Cases treated by surgical operation}

Demonstration of antigen. Co-A detected CAg in preoperative sera of all six new cases treated surgically (Table 1). The test demonstrated antigen in three postoperative sera (case nos. 4, 5 and 6) collected on the third day. Serum samples from the other three cases (case nos. 1, 2 and 3) were not available for testing. The test also detected antigen in four of five postoperative sera (case nos. 1, 2, 3 and 4) collected on the seventh day after treatment. One serum sample (case no. 5) was negative for $\mathrm{CAg}$ while another serum sample (case no. 6) could not be obtained from the patient, hence was not available for testing.

CIEP demonstrated CAg in the pre-operative sera of four patients (case nos. 2, 3, 5 and 6). CAg was not detected in sera of the remaining two cases (case nos. 1 and 4). All post-operative sera collected 3 days, 7 days, 1 month, 6 months and 1 year after surgery were negative for $\mathrm{CAg}$ by CIEP.

Pre-operative sera from seven old cases (case nos. $7-$ 13) were not available, hence could not be tested for CAg. Co-A and CIEP demonstrated CAg in four sera (case nos. 8, 9, 11 and 13) and two sera (case nos. 8 and 11), respectively, collected 2 years after surgical removal of cysts. 
Table 1. Serum antibody and antigen profiles in hydatid disease followed up to 2 years after treatment

\begin{tabular}{|c|c|c|c|c|c|c|c|}
\hline \multirow[b]{2}{*}{ Case no. } & \multirow{2}{*}{$\begin{array}{l}\text { Before } \\
\text { treatment }\end{array}$} & \multicolumn{6}{|c|}{ After treatment } \\
\hline & & 3 days & 7 days & 1 month & 6 months & 1 year & 2 years \\
\hline \multicolumn{8}{|c|}{ IHA } \\
\hline \multicolumn{8}{|c|}{ New surgical cases: } \\
\hline $\begin{array}{l}1 \\
2\end{array}$ & $\begin{array}{l}256 \\
128\end{array}$ & & $\begin{array}{l}8 \\
2\end{array}$ & & & & \\
\hline 3 & 1024 & & 128 & 64 & & 32 & \\
\hline 4 & 64 & 64 & 64 & 2 & 1024 & & \\
\hline 5 & 4 & 512 & 32 & & & & \\
\hline \multirow{2}{*}{\multicolumn{8}{|c|}{ Old surgical cases: }} \\
\hline & & & & & & & \\
\hline 7 & 2 & & & & & & 32 \\
\hline 8 & 32 & & & & & & 32 \\
\hline 9 & 2 & & & & & & 512 \\
\hline 10 & & & & & & & 256 \\
\hline 11 & 2048 & & & & & & 256 \\
\hline 12 & & & & & & & 512 \\
\hline \multirow{2}{*}{\multicolumn{8}{|c|}{ Chemotherapy cases: }} \\
\hline & & & & & & & \\
\hline 14 & 512 & & & & & 2 & \\
\hline 15 & 512 & & & & 32 & & \\
\hline 16 & 1024 & & & & 16 & & \\
\hline 17 & 1024 & & & & & 1024 & \\
\hline 18 & 256 & & & & 128 & & \\
\hline \multicolumn{8}{|c|}{ Co-A } \\
\hline \multicolumn{8}{|c|}{ New surgical cases: } \\
\hline 1 & 128 & & 16 & & & & \\
\hline 2 & 32 & & 16 & & & & \\
\hline 3 & 8 & & 8 & 0 & & 0 & \\
\hline 4 & 32 & 16 & 8 & 0 & 0 & & \\
\hline 5 & 32 & 8 & 0 & & & & \\
\hline 6 & 64 & 16 & & 0 & & & \\
\hline \multicolumn{8}{|c|}{ Old surgical cases: } \\
\hline $\begin{array}{l}7 \\
8\end{array}$ & & & & & & & 0 \\
\hline $\begin{array}{l}8 \\
9\end{array}$ & & & & & & & 16 \\
\hline 10 & & & & & & & 2 \\
\hline 11 & & & & & & & $\begin{array}{l}0 \\
4\end{array}$ \\
\hline 12 & & & & & & & $\begin{array}{l}4 \\
0\end{array}$ \\
\hline 13 & & & & & & & 8 \\
\hline \multicolumn{8}{|c|}{ Chemotherapy cases: } \\
\hline 14 & 8 & & & & & 0 & \\
\hline 15 & 128 & & & & 0 & & \\
\hline 16 & 16 & & & & 0 & & \\
\hline 17 & 32 & & & & & 0 & \\
\hline 18 & 0 & & & & 0 & & \\
\hline \multicolumn{8}{|c|}{ CIEP } \\
\hline \multicolumn{8}{|c|}{ New surgical cases: } \\
\hline 1 & - & & - & & & & \\
\hline 2 & + & & - & & & & \\
\hline 3 & + & - & - & - & & - & \\
\hline 4 & $\begin{array}{l}- \\
+\end{array}$ & - & - & - & - & & \\
\hline $\begin{array}{l}5 \\
6\end{array}$ & + & - & & - & & & \\
\hline Old surgic & & & & & & & \\
\hline 7 & & & & & & & - \\
\hline $\begin{array}{l}8 \\
0\end{array}$ & & & & & & & + \\
\hline $\begin{array}{r}9 \\
10\end{array}$ & & & & & & & - \\
\hline $\begin{array}{l}10 \\
11\end{array}$ & & & & & & & - \\
\hline 12 & & & & & & & ${ }_{-}^{+}$ \\
\hline 13 & & & & & & & -_ \\
\hline Chemother & & & & & & & \\
\hline 14 & - & & & & & - & \\
\hline 15 & + & & & & - & & \\
\hline 16 & + & & & & - & & \\
\hline 17 & + & & & & & - & \\
\hline 18 & t & & & & - & & \\
\hline
\end{tabular}

Demonstration of antibodies. Sera showing an antibody titre of $\geqslant 128$ by IHA were considered to be positive for hydatid disease.

IHA demonstrated diagnostic CAb titres of $\geqslant 128$ in four pre-operative sera (case nos. 1, 2, 3 and 6). Two other sera (case nos. 4 and 5) were negative for $\mathrm{CAb}$ by IHA. CAb titres in post-operative sera collected at different times ( 3 days, 7 days, 1 month, 6 months and 1 year) showed variable CAb titres (Table 1). 
Post-operative sera from five old cases (case nos. 9, $10,11,12$ and 13) operated for hydatid cysts 2 years previously showed a diagnostic CAb titre of $\geqslant 128$ by IHA. Two sera were negative for CAb.

\section{Cases treated by chemotherapy}

Demonstration of antigen. Co-A detected CAg in four pre-chemotherapy sera (case nos. 14, 15, 16 and 17) out of a total of five cases. No CAg was detected in three (case nos. 15, 16 and 18) and two (case nos. 14 and 17) post-chemotherapy serum samples collected 6 months and 1 year after therapy, respectively.

CAg was detected in four pre-chemotherapy serum samples (case nos. 15, 16, 17 and 18) by CIEP. CAg was not detected in one serum sample (case no. 14). $\mathrm{CAg}$ also was not detected in any of three sera (case nos. 15, 16 and 18) and two sera (case nos. 14 and 17) collected on 6 months and 1 year after chemotherapy, respectively.

Demonstration of antibody. All five pre-chemotherapy sera were positive for $\mathrm{CAb}$ by IHA. Of these, one serum (case no. 18) collected 6 months after chemotherapy and another serum (case no. 17) collected 1 year after chemotherapy were still positive for $\mathrm{CAb}$ by IHA.

\section{Discussion}

ELISA is frequently used to detect CAg in hydatid disease $[5,10,11]$. CIEP [6] and Co-A [7] are the other two tests that have been standardised and evaluated for the first time in this laboratory to demonstrate CAg in serum for the diagnosis of hydatid disease. CIEP is a highly specific test ( $100 \%$ specificity) and no false positive reactions were observed with any sera from the diseased patients or healthy controls. The test is moderately sensitive [6]. Co-A is relatively more sensitive $(95 \%)$ but less specific $(84 \%)$ than CIEP. False positive reactions were observed with sera from patients with various other parasitic diseases [7]. Both the tests are simple, inexpensive and rapid, with results obtainable within $1 \mathrm{~h}$ after receipt of the serum. These two tests have a potential for wider application in the serodiagnosis of hydatid disease in poorly equipped laboratories in developing countries [12].

The demonstration of circulating hydatid antigen is useful in post-treatment evaluation of cases $[10,11]$ : In this study, a total of 11 pre-operative or prechemotherapeutic sera collected from six new cases of surgically treated hydatid disease and from five cases of PHD and USP cases treated with chemotherapy were screened for the presence of CAg by both CIEP and Co-A. Of these, 10 and eight sera were positive for CAg by Co-A and CIEP, respectively. The postoperative sera collected from these cases did not show any CAg by the CIEP test. However, CAg could be detected by Co-A in three and four of these sera collected 3 and 7 days after surgical removal of the cyst, respectively (Table 1). The CAg level in the sera showed a marked decline by the seventh day after surgical removal of the cyst (Table 1). CAg could not be detected by Co-A in the sera collected 1 month after surgery and 6 months after chemotherapy.

Serum samples from seven 'old' cases of hydatid disease (patients who were operated on 2 years previously), were tested for the presence of CAg. Of these seven sera tested, all except two were negative for CAg by both CIEP and Co-A tests. The clinical presentations of these two cases, sera of which were positive for the antigen, showed that the infection was still persisting with signs of active clinical disease. This could be due to recurrence of the disease by secondary echinococcosis or persistent and undetectable small hydatid cysts elsewhere in the body [7]. Detection of CAg in two more cases by Co-A but not by CIEP may be false positive reactions in the $\mathrm{Co}-\mathrm{A}$ test [7].

Unlike serum CAg profiles, no marked differences were noted between the $\mathrm{CAb}$ profiles of the pre- and post-treatment sera of both surgical and chemotherapeutic cases of hydatid disease, as shown by IHA. Six months after surgery or chemotherapy, two cases (case nos. 17 and 18) (Table 1) showed a marginal decrease in their serum antibody titres. Circulating antibodies of varying titres were still detectable in all seven serum samples of old cases of hydatid disease 2 years after surgical removal of the cysts.

The findings of this study confirm similar observations in a preliminary study of serum $\mathrm{CAb}$ and $\mathrm{CAg}$ profiles before and after surgical removal of hydatid cysts in three cases of hydatid disease [7]. The detection of $\mathrm{CAg}$ is useful in detecting antibody-negative hydatid cases and also in assessing the status of infection, whether recent or past. In addition to this, the results of the present study suggest that both pre- and postsurgery or chemotherapy estimation of CAg in serum would be useful in monitoring post-operative or chemotherapeutic cases of hydatid disease and to determine whether the patient is cured of hydatid disease or still has active infection.

\section{References}

1. Bhatia BB, Pathak KML. Echinococcosis. In: Parija SC (ed) Review of parasitic zoonoses. Delhi, AITBS Publishers and Distributors. 1990: 268-280.

2. Parija SC, Rao RS, Badrinath S, Sengupta DN. Hydatid disease in Pondicherry. J Trop Med Hyg 1983; 66: 113-115.

3. Parija SC. Recent trends in the serodiagnosis of hydatid disease. Southeast Asian J Trop Med Public Health 1991; 22 Suppl: $371-376$.

4. Parija SC. New approaches in the serodiagnosis of hydatid disease. J Indian Med Assoc 1994; 92: 281-284.

5. Gottstein B. An immunoassay for the detection of circulating 
antigens in human echinococcosis. Am J Trop Med Hyg 1984; 33: $1185-1191$.

6. Shariff GM, Parija SC. Counter-current immunoelectrophoresis for serodiagnosis of hydatid disease by detection of circulating hydatid antigen. J Microbiol Methods 1991; 14: 71-76.

7. Shariff GM, Parija SC. Co-agglutination (Co-A) test for circulating antigen in hydatid disease. J Med Microbiol 1993; 38: $231-234$

8. Parija SC, Ananthakrishnan N. Evaluation of stabilised cells in the indirect haemagglutination test for echinococcosis. $J \mathrm{Med}$ Microbiol 1985; 19: 95-98.

9. Parija SC, Rao RS. Enhancement of sensitivity of the haemagglutination test for echinococcosis by use of Staphylococcus aureus protein A. J Med Microbiol 1986; 22: 241-244.

10. Craig PS, Nelson GS. The detection of circulating antigen in human hydatid disease. Ann Trop Med Parasitol 1984; 78: 219-227.

11. Kanwar JR, Vinayak VK. The significance of free and immuno-complexed hydatid-specific antigen(s) as an immunodiagnostic tool for human hydatidosis. J Med Microbiol 1984; 37: $396-403$.

12. Parija SC. Simple immunoassays in the serodiagnosis of hydatid disease at the field or poorly equipped laboratories. Indian J Med Microbiol 1993; 11: 1-4. 